fatal side-effects of antidiphtheritic serum are simply due to the fact that the patients have been tuberculous, so being much more amenable to the toxic influence of the serum than are otherwise normal individuals.

In tuberculosis serotherapy this point is of the greatest importance, and accounts for so many of the so-called failures. As soon as it is noticed that a patient suffers under the injections (general depression, local infiltration and painful inflammation, sometimes localized necrosis), the treatment has to be abandoned. But it must be remembered that these occurrences have notbing to do with the antitoxic property of the serum. Fortunately a great number of tuberculous individuals are exempt from this additional susceptibility.

As yet it is hardly worth while to enter into a critic review of the different reports published. If we consider that any serum, prepared after a proper method, by the treatment with tuberculosis toxins of whatever form, is bound to have some antitoxic quality, and that the differences between the several serums used are merely quantitative and not qualitative (although I know of antitubercular serums for the preparation of which neither tuberculin nor anything else was used for a long series of months), it becomes annoying to read that with such and such a serum good results have been obtained, while another one has proved to be absolutely ineffective. Usually the serum offered in a commercial way is found to be worthless, while the value of those distributed free on the part of the Government, or from some other "unselfish" party, is extolled (Stubbert). Hypocrisy and trickery even enter the realms of scientific reports. After a while these shadows will pass away. I sum up my remarks in this sentence: All antitubercular serums, if properly prepared, are antitoxic. The potency of those must be highest in which the highest and most powerful doses of toxins have been used for immunizing purposes, and for which every scientific attainment has been made available.

As to the cases of which notes are given in the appended table, I do not want to draw any conclusions from them. I only selected these cases because I have been able to observe them for periods of twelve to eighteen months, $O:$ to attend to them until the exitus. All those cases that have been treated only temporarily or not regularly, or only for a short time, are excluded. The result so far is that of 21 cases, 13 derived considerable improvement. I even think that the next few years will show that they overcame the disease. One more case is doing so well that for him, too, a good prognosis may be allowed. Three cases seemingly derived no benefit, while 4 cases, which from the beginning were hopeless, died during the treatment. Decided improvement, therefore, has been brought about in 62 per cent.-it would be justifiable to exclude the 4 cases which died, and thus arrive at the figure of 76 per cent. Whether it was the serum or something else that did this, I do not want to discuss. I would especially call the attention to the tuberculin tests made. Everything will explain itself by a study of the table, in which I did not make any attempt at classifying the cases according to the socalled stages of the dizease.

LITERATURE.

C. Fisch: The antitoxic, etc., value of the serum of horses treated with Koch's new tuberculin, Journ. Amer. Med. Assn., Oct., 1897.

Behring: Elrlich, Koch, $\nabla$. Lingelsheim in 'Deutsche Med., Wochenschrift, 1898, No. 19,37 , etc., 1899 .

Ehrlich: Berl. Klin., Woch., No. 1, 1899.

Gautier: les toxines, Paris, 1896, p. 542 ff.

Ehrlich: Klin. Jahrbuch., Vol. vi, (Testing of diphthera antitoxin).

\section{THE BRAIN AND ITS FUNCTIONS.}

A SUMMARY, PART I.

BY J. SANDERSON CHRISTISON, M.D. CHICAGO.

The part of the brain which has been most studied is its gray-matter covering or cortex, which entirely surrounds its hemispheres except at their points of union. Owing to the peculiar formation of the brain into convolutions or gyri, which form more or less deep infolds or fissures, the deepest of which serve to divide the brain into lobes, only about one-third of the cortex appears externally. The thickness of the cortex varies at different locations and points, rang. ing from 1.5 to $4 \mathrm{~mm}$. Toward the front of the brain, and especially at the summit of the pre-central convolution, in what are commonly known as the sensory-motor areas, the cortex is not only the thickest, but its cells are the largest, while in the visual areas at the back of the brain the cortex is the thinnest while it is also the densest. ${ }^{1}$

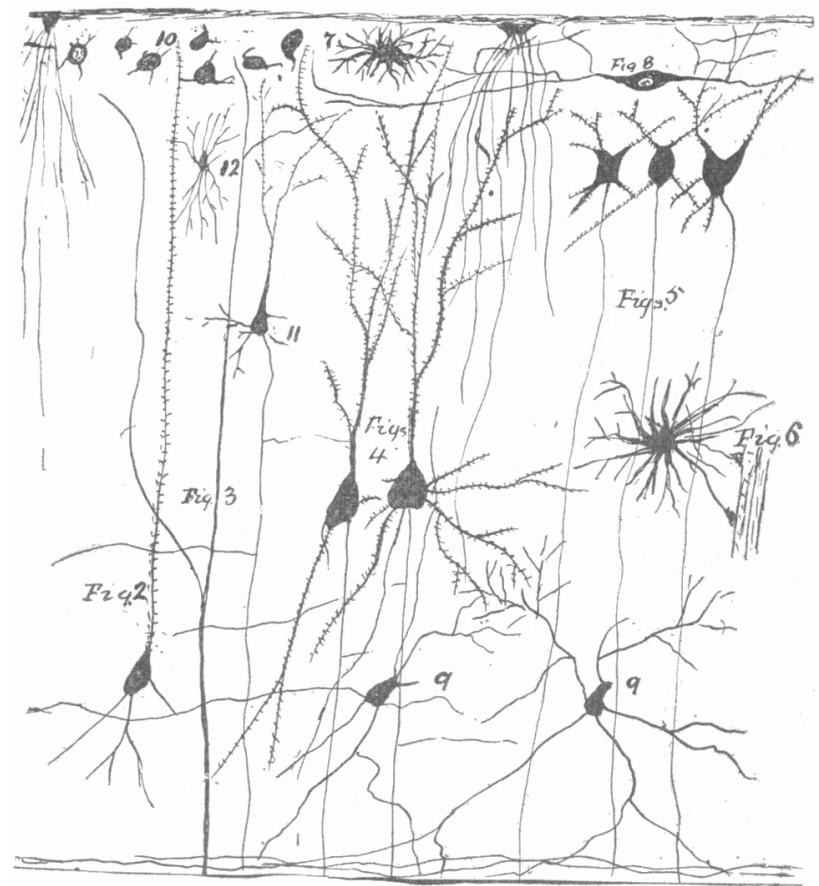

Fig. 1.- Showing the common forms of the cells in the cortex of the Fusiform nerve-cell. sensory). 4. Pyramidal nerve-cells inotor. 5 Forms of pposed to be Protoplasmic neurogliar cell attached to an artorms of motor cells. 6. layer. 8. Spindle cell. 9. Polymorphic cells. 10. Granular cells. 11. Small
pyramidal cell. 12. Spider cell.

While minute but very elastic blood-vessels and lymphatic canals exist in great abundance within the cortex, its constituents of chief interest are the cells of various forms which are stationed in a more or less orderly arrangement of layers, the number of which is variously estimated at from three to eight, while five is the number usually imputed. While Golgi, Cajal, Goltz, Von Köelliker and most other investigators agree that parts of the cortex having different functions show throughout essentially the same structure, Flechsig asserts he has found a form of cell peculiar to one location, viz., the large spindle cell of Branca in the gyrus fornicatus.

A microscopic view of a cross-section of the cortex reveals what much resembles a forest of uprooted shrubs in winter bud, and associated with other forms of cells variously named, spindle, spider, neurogliar, molecular and granular, according to their forms. 
The shrub-like cell, which is usually the largest, is called the pyramidal cell, owing to the commonest form of its cell-body or bulb, which is said to be sometimes visible to the naked eye. ${ }^{2}$ As many as twenty processes or dendrons may grow from a single cellbody, the chief one growing in the direction of the surface. Some of these dendrons have many branches, which all grow at acute angles to the main stem. The tiny bud-like processes upon these tree-like branches are supposed to be the points of contact and communication with other cells. and to generate or receive energy or impulses from surrounding matter.

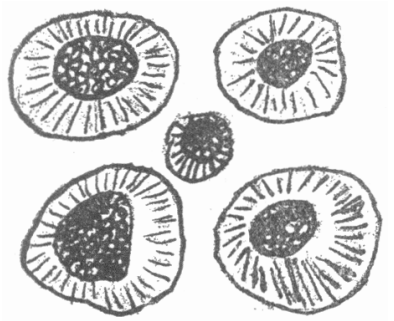

Fig, 2-Section of nerve-fibers showing the tubular appearance of the fibrils of the axis-cylinder (after Schäfer)

From a point in the cell-body, usually oppusite the main dendron, there projects at least one process or neuron which also gives off branches, but fewer and at right angles to the main stem, while the main stem passes into the white substance of the brain and onward to a near-by or remote point within the brain or spinal cord. These neurons are the first procesces which develop from the cell-bodies. But, while the cell-body is parent to both dendron and neuron, it eventually sustains no more structural relationship to them than that of propinquity, for these two offshoots join ends to form what appears to be a cylindric rod,

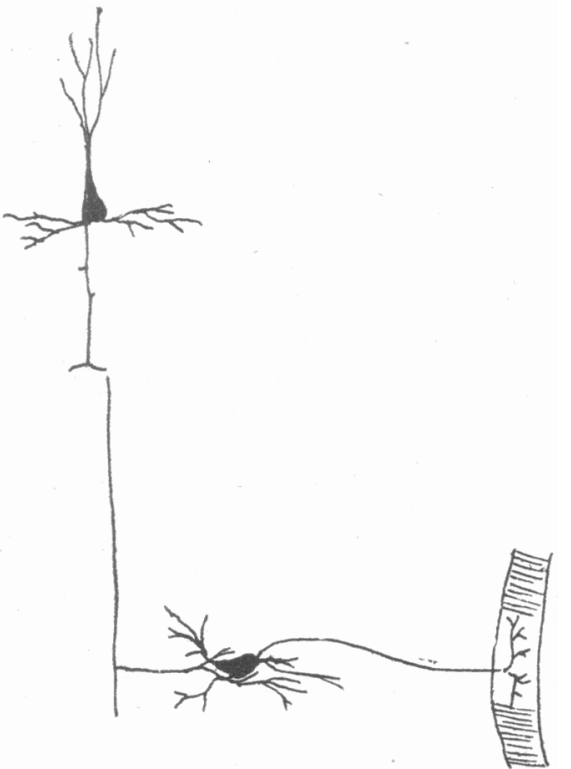

FIG. 3.-Motor nerve-cell connecting with muscle (after Edinger). containing as many as fifty fibril ${ }^{3}$ which pass through the cell-body without interruption. Because of this structural development it is supposed that impulses do not originate in the cell-body, but in or at the buds of the dendrons. The cell-body, however, seems to remain the vital center. The cell in its completeness - bulb, neurons and dendrons-constitutes an isolated anatomic unit, which associates but does not fuse with other cells or fibers, although its dendrons may extend to the surface of the cortex, and its neurons as far as the lumbar region of the spinal cord.

\section{DEVELOPMENT OF THE CELL.}

Within the first month of embryonic development, and while the brain resembles a distorted tube with here and thera a bulge, the cortical cells have begun to appear as minute spheric objects, each of which develops a nucleus which contains one or two minuter bodies or nucleoli. These cells rapidly divide, one daughter cell remaining as the germinal cell, while the other migrates to become a fully fledged nerve-cell." This process goes on for about two months, after which the cells seemingly cease to multiply, but gradually increase in size from 1 to 500

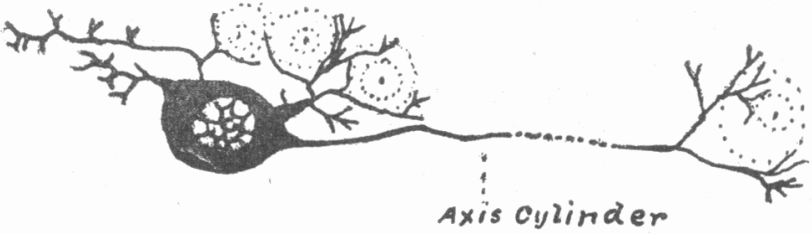

FIG, 4. -Diagram of sympathetic ganglion-cell (Ritzius).

times. ${ }^{5}$ They do not obtain their full growth until puberty or after, when the largest may measure at base $1 / 300$ inch in diameter and four or five times more in length, while its neurons and dendrons have made proportional gains in length and thickness. Neurons which at birth measure in diameter from 1.2 or $2 \mu$ to 7 or $8 \mu$, become at maturity 10 to $15 \mu$ respectively for the largest. The number of cells in 0.1 cubic $\mathrm{mm}$. varies from five or six to ninety, but generally from ten to twenty, ${ }^{6}$ or more than three and a half billions in a brain. and constituting about one-tenth its total weight. ${ }^{4}$

The neurone and dendrons gradually become enveloped in a fine medullary sheath which is regarded as both insulating and nutritive in its functions. Only

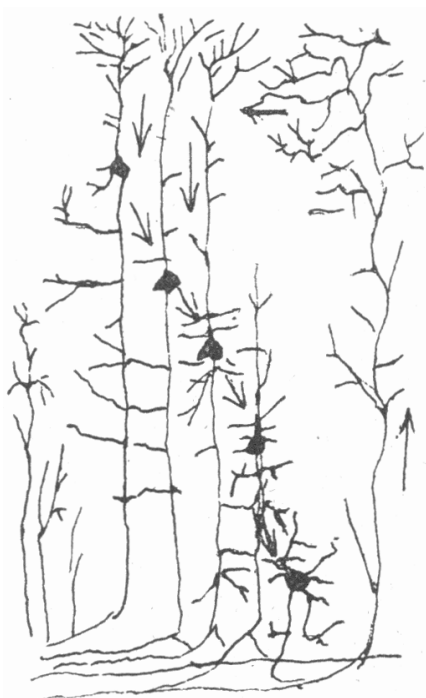

FIG. 5.-Sensory and motor brain-cells--showing their interrelation as afferent and efferent neurons to the cortex, according to the idea of Cajal. a small proportion of the nerve-fibers of the cerebrospinal system have no sheaths, while on the other hand very few of the fibers of the sympathetic system have any sheaths whatever. Some fibers of the sympathetic system do not functionate until they possess a sheath, and some do not have a sheath until late in middle life and many have none even then. But all sheathed fibers are exposed at their extremities.

Some cells seem never to develop beyond their first stage, while the lifetime of an individual cell may be co-extensive with the life of the person, for as 
Virchow observes, "all cells destined for the highest animal functions prove sterile, or at least very hypothetically capable of proliferation."7 However, pro. liferation of brain.cells has lately been observed in some mature lower animals, ${ }^{8}$ while the "fungus" growths following injuries of the brain contain brain tissues, ${ }^{9}$ thus showing either a rapid proliferation or a rapid maturing of undeveloped cells, for it is a recognized histologic, as well as a pathologic law that cells can only produce cells which are identic with them in constitution and function.

The brain-cells are very elastic and resistant to pressure, requiring considerable force to destroy their contour and break their processes. ${ }^{2}$ In their bulbs a small amount of yellow pigment is normally found, and which is supposed to represent bygone functional activity. This pigment is usually absent in idiots and imbeciles. The rest of the cell-body is composed of granular matter surrounding the nucleus. Braincells discharge impulses at the rate of ten per second, ${ }^{10}$ with a speed, according to Hammond, of 100 to 120 feet per second for motor nerves and about 24 feet per second for visceral nerves.

VASCULAR SUPPLY OF THE CORTEX.

In its supply of blood-vessels the cortex is independent of the cther parts of the brain, and it is said that it can maintain its functional activity even when three of its four arteries are obliterated. Autopsies upon cases of sudden death not infrequently disclose the fact that owing to obstructive organic disease of the heart, a greatly reduced circulation of blood has sufficed to maintain the requirements of the brain for ordinary purposes. In the case of a late prominent merchant and philanthropist of Chicago, who sud. deniy died amidst many interests, Professor Favill tells me that an aortic stenosis was found so great that the blood-current must have been reduced to about one-tenth the normal amount. Unlike other arteries of the body the arteries of the brain rarely fuse together. It has been thought that they were devoid of nerve-fibers, but that has been disproved by Oberstiner, Morison ${ }^{11}$ and others. It has also been observed that when the other arteries of the body are calcified by disease the arteries of the brain remain soft and yielding. ${ }^{12}$ The vast number of small bloodvessels and capillaries within the brain not only afford it a liberal supply of nutriment, but serve as an elastic padding to the cells and fibers, which are sup. ported in position by an abundance of fine connective tissue, which, with the blood-vessels, constitute about one-fourth of the entire brain mass. ${ }^{4}$

\section{BASAL GANGLIA.}

As yet but little is known of the corpus striatum, the optic thalamus and the corpus quadrigeminum. Lesions of the corpus striatum produce paralysis of the opposite side of the body without mental symp. toms; lesions of the optic thalamus produce loss or impaired sensation of the opposite side of the body.13 Monokon believes every part of it is connected with some part of the cortex, ${ }^{1+}$ and according to the same authority it contains numerous cell bundles not found in the brains of lower animals. Lesions of the corpus quadrigeminum commonly produce blindness. Sterling and Landois regard it as a co-ordinating center. The cerebellum appears as functionally homogeneous. Lesions of it produce defects of muscular movement, while sensation remains intact, and instinct and intellect are unaffected. Each half controls mainly the muscles of its own side. The pons and medulla contain numerous gray-matter bodies regarded as internodules, some of which are peculiar to the human brain.

\section{CHEMIC COMPOSITION.}

From a chemic point of view, the ingredients of the brain are more numerous, more intricately constituted and more diversified than those of any other organ or system. It contains more than three hundred different chemic constituents, and those peculiar to the brain are endowed with great stability in a chemic sense and with great sensitiveness to reacting influences from without. ${ }^{15}$

In gray matter there is 85 per cent. water and 1 per cent. ash, while in white matter there is only 70 per cent. water and 1.7 per cent. ash. The average specific gravity for gray matter is 1034 and for white matter 1041. ${ }^{16}$ In the insane the average (thirty cases all kinds ${ }^{1}$ ) is for white matter the same as normal, but for gray matter it is 1037, or a trifle heavier than in the sane.'

\section{GROWTH AND DECLINE OF THE BRAIN.}

At birth the brain weighs about 12 per cent. of the whole body or an average of $340 \mathrm{gm}$. for males and $330 \mathrm{gm}$. for females. It is, therefore, nearly onefourth its size at maturity, when it weighs only about

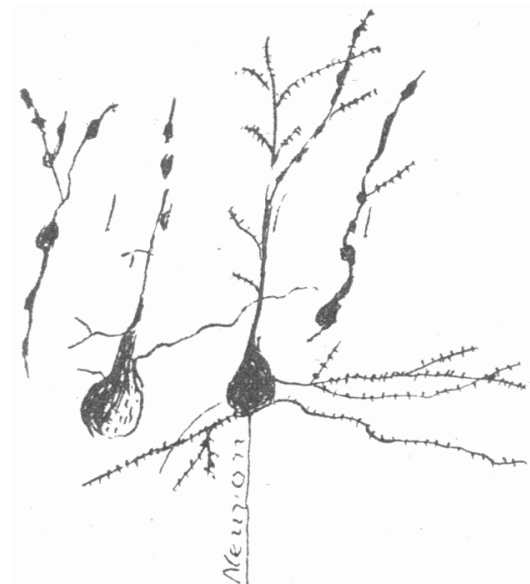

Fig. 6.-Alcoholic degeneration of the cortical nerve-cells-various stages.

2 per cent. of the whole body. During the first nine months after birth the brain gains about one-third its whole increase and by the eighth or ninth year it has attained nearly its full growth. ${ }^{17}$ Dr. Robert Boyd found that the brains of boys between the ages of 4 and 7 weighed on an average $1214 \mathrm{gm}$., and about the same for girls; but boys between 7 and 14 years of age gave a brain weight of $1410 \mathrm{gm}$., while girls between the same years gave a brain weight of only 1265 $\mathrm{gm}$. These children were from the poor of London. ${ }^{21}$ According to Fuchs and Vulpius, the brain is not fully organized until 7 or 8 years of age, at which stage its growth makes a pause until puberty, when it again makes a rise. Donaldson has pointed out that the curve for brain weight ordinarily shows a rise until the age of 55 years, while in the case of eminent men it shows a rise until 65 years of age, when it begins to decline. ${ }^{18}$ After birth the most active period of brain growth is during the first four years.

The babe at birth is physiologically but little more than a "spinal thing," as Virchow long since termed it when its structure was less known than now. At this stage but little else than the spinal cord and medulla contain perfected nerve-fibers, which gradually 
extend upward to meet those developing from the cortex. According to Flechsig, those from the bodily-sense area of the cortex appear first and are fol. lowed by the appearance of fibers for the sense of smell. A month or so later the fibers for vision organ. ize, and by about the third month after birth the fibers for the sense of hearing and volitional acts begin to mature.

In adults the increase of the brain is due to the growth of the cortical cells, the embryonic cells, and the other related structures. In old age the cells become heavily pigmented, while they atrophy, and many of the fibers are substituted by connective tissue. In senile dementia the spider cells increase in number. According to Althus, deaths from nervous diseases (excluding infant eclampsia) are only 7 per cent., and a large proportion of these are primarily due to diseases of the blood-vessels. Thus it is evident that while in health it suffers the least of all organs from a general starvation, it also suffers the least from dicease. Its reparative and adaptive powers are greatest before the cells and fibers are fully formed, when broken fibers may unite and new fibers develop.

\section{FUNOTIONING OF THE CELLS.}

The brain requires regular sleep and food, but especially sleep. Dogs, which can live for twenty days without food, can not live more than five days without sleep. ${ }^{19}$ Man's limit of endurance without sleep is estimated at ten days. Some persons, especially seamen, soldiers and nurses can, like Napoleon, sleep for a few minutes at a time and awaken at any irregular hour desired. Before a great event with great anxiety, sleep comes, and it has been known to be so intense that a foot has been burnt to a cinder without resilizition of the fact until afterward. ${ }^{26}$ Sleep is thought to be due to a retraction of the dendron buds, thus breaking contact, and so interrupting or enfeebling the circuits of vitality between motor and sensory cells. That such an action is caused by an overloading of waste matter resulting from fatigue is quite unlikely, for in sound, normal sleep the circulation is greatly reduced in volume and force, indicating a correspcnding reduction of metabolism and general functional activity. Normal sleep would rather seem to be due simply to the more or less exhrustion of the cells having an inherent demand for the restoration of their reacting power. The brain-cells can not be regarded as reservoirs of vital energy, but their power to react must correspond with their energizing efficiency, dependent upon nutrition as occasions demand, the demand being constant but fluctuating.

Defective functioning of the brain-cells is expressed by sensory, motor and intellectual irregularities or inefficiencies. As abnormal conditions of the cells connected with the special senses must necessurily deliver wrong impressions at their centric ends, and thus discharge a wrong suggestive influence on the mind, the result is a misinterpretation or hallucination, but which may be corrected if the brain-cells in general are not too inefficient to preclude the requisite amount of attention (reasoning) to secure the correction.

Delusions are due to a more or less general ineffi. ciency of the brain-cells, reducing the vital energy below what is required for effective attention or the proper association of related ideas, while the character of the delusions, whether exalted or depressed, will depend not only upon the character and environment of the subject but also upon those particular bodily organs (especially the glands) most perverted in function. All bodily organs have their special sug. gestive influence upon the mind through their neural centers in the brain, for in this way they constantly influence our feelings so that by their normal and harmonious action the sense of well-being is experienced. Indeed, the treatment of insanity is as a rule chiefly a matter of glandular concern-of digestion, secretion and elimination. Idiopathic insanity or toxic insanities have no other pathology except in their final stages. Illusions have the particular factor of expectancy, conscious or subconscious, in reference to a particular external object.

The peculiar affections of memory, or rather of recollection, which are classsed as aphasias, sometimes seem to be due to localized affections of the sense centers or their connections, producing an uncompensated loss of an established and special physiologic correlate to a subtle mental process. Such localized affections, however, can only be causative through a peculiar suggestive influence which in a negative or subconscious way inhibits ideational associations along special lines. So subtle are some of the association principles of the mind that certain groups of memory signs closely allied to others may be temporarily forgotten, while the others are readily recalled, as a bird without its feathers. For example, a person may be able to speak or write numerals while at the same time unable to recall the letters of the alphabet. This is explained by the fact that numerals are associated by the stronger law, as they represent the simplest kind of natural relationship in order and space, whereas the alphabet represents an artificial association of differing qualities. Thus, as in the crse of insanity proper, the most natural and earliest established habits persist the longest with the subject.

All mental defects whatever are correlative to abnormal or inefficient brain-cell reaction while, on the other hand, brain.cells can not in any way hold memory images or sensory impressions of any kind, as every new impression must destroy the preceding, even if there was not a constant chemic change going on within them. Certain toxic drugs, especially those belonging to the order of Atropacia can produce aphasias and insanity.

In accordance with the views here expressed, convulsions are due to inco-ordinate action of associated sensory and motor organs, but originating from a perversion somewhere besond them in the sympathetic system. The exhaustion which follows a fit expresses a general loss of reactive power in the cells rather than the production of a "discharging lesion" of any particular area.

\section{REFERENCES.}

1. Simpson: Jour. Ment. Sci. Oct. 1898, also Oberstiner and others.

Turner: Jour. Ment. Sci., July, 1898.

Oberstiner: Quoted by Gowers

dson: American Text-Book of Physiology.

Ayers: Jour Compar Nurnook of Physiolon

Hammarber. Studien über Klinik a Patlologie der Idiots nebst snchenger iiber den normales Band der Hirnrinde, 189.

Vircliow: Huxley Eect. Lancet Oct, 8, 1898

Herrick: Proceedings of the Cincinnati Soc. of Nat. Hist., Jan. 90. Ayers: Jour. Compar. Neurology, Vol, i, p. 3 .

9. Phelps, N. Y. Med. Jour., Oct. 1, 1898.

10. Schiffer: Brain, 1893, p. 165.

11. Morison: Edin. Med. Sour., January, 1899, p. 31

. Balfour: The Senile Heart, 1894. Beneke: Die Alteris Dispositions. Sellier and Verger: Archives de Physiologie, Oct.. 1898.

14. Monokow: Quoted by Barker, Jour. Nerv. and Ment. Dis., Nov.,

15. Thudicum: Tukis Dict. of Psycho. Med.

6. Sankey: Brit. and Foreign Medico-chirurgical Rev. Vol. xi

17. Vierordt: From an examination of 415 males' and 424 females' brains ranging in age up to 25 years, Quoted by Burke. Pedagog. Sem.,
Oct., 1898. 
18. Donaldson: Growth of the Brain

19. Racudrip: Proceed. Internat. Med. Cong., Rome, 1894.

20. Carpenter: Principlos of Human Physiology (H.

\section{CEREBELLAR ABSCESS OF OTITIC ORIGIN-AUTOPSY.*}

\section{BY A, D. McCONACHIE, M.D.}

Assistant Surgeon to the Presbyterian Eye, Ear and Throat Charity Hospital; Ophthalmologist to Bay View Almshouse.

\section{AND C. W. HARTWIG, M.D.}

BALTIMORE, MD.

The importance of prompt and early arrest of pur. ulent conditions in the middle ear is becoming more and more firmly fixed in the mind of every physician. It is only within recent years that anything like success has been attained in the treatment of these conditions. The pathologic and etiologic fartors in such cases are being more thoroughly studied and better understood. We are, to-day, better able than ever before to appreciate the extreme gravity of such conditions and now know that a chronic otorrhea-like a pocketful of dynamite-is a standing menace to life instead of, as formerly, being considered a mere in. convenience. We now regard the condition seriously and do not rest satisfied until the discharge is cured.

Nearly 20 per cent. of all ear cases belong to the class of otorrheas. Suppurative processes in the drum cavity readily lead to necrosis and destruction of the bony walls of the tympanum with involvement of mastoid antrum and cells, penetration of lateral sinus and involvement of meninges or brain itself, with abscess formation. Any one with an acute or chronic purulent process in the middle ear is liable to have, with slight warning, a most serious or even fatal ill. ness. Youth being the most frequent age in which the prevailing etiologic conditions and diseases exist, it would be interesting to know the numbers who yearly die as a result of such conditions.

The knowledge of the causal relation which nasopharyngeal diseases bear to suppurative conditions in the middle ear is rendering the treatment much more effective. Hypertrophy of pharyngeal tonsil -adenoids--enlarged tonsils, deviated septum, spurs, enchondroses, polypi and hypertrophied turbinals are the primary causes of more otorrheas than all other causes combined, especially when present during an attack of the acute infectious diseases, as influenza, measles, scarlet fever, diphtheria, etc. The complete removal of these obstructive conditions to respiration, and proper ventilation of the tympanic cavity is often all the treatment that is necesssry if the case is seen early, before any necrotic process has taken place in the tympanic or neighboring structures. At present our German cousins have become extremists and adopt ultraradical measures in all chronic suppurations, by treating such conditions by the mas. toid operation. When indicatel, it undoubtedly should be done and done promptly, but other and more conservative measures should first be given a fair trial. I would not be understood to say that conservatism is synonymous with good sense at all times. There is a time when delay is dangerous and hesitancy may cost the life of the afflicted. For just such cases as these the radical surgical procedure --tympanomastoid-is necessitated. Radical treatment means the institution of active surgical measures-as much as and no more than is necessary, as against the delay,

\footnotetext{
*Read before the Clinical Society of Maryland, March 17, 1899.
}

linger-and-wait methods of the ultraconservatives. My application of radical advances in such conditions begins with the use of surgical good sense at the right time. These surgical measures may begin with the removal of adenoids or other obstruction to free respiration or tympanic drainage. It may mean the incision of a drum at the right time for removal of purulent contents in the drum cavity; it may mean the removal of carious or necrotic ossicles or tissues therein; it may mean the thorough intratympanic washing by antiseptics, or it may (now restricted to this sphere) mean the opening of the mastoid antrum and cells and removal of other tissues, made neces. sary by involvement in the diseased process-as the tympanic structures, or opening into the cranial cavity for the purpose of evacuating an abscess formation. In spite of our best efforts-medical and surgicalmany of these cases follow the course of the inevita. ble, as is illustrated by the following case, for my interest in and knowledge of which 1 am indebted to my friend, Dr. Hartwig:

Case 1.- On the evening of February 2 last, I was asked to see, in consultation with Dr. Hartwig, a boy 12 years of age, who had a history as follows: Right ear had been discharging for three years, following convalescence from typhoid fever. Before that time the boy was robust, always well and cheerful. The usual measures for the arrest of the otorrhea were employed by his family physician, with frequent cessation of discharge, to recur at intervals. The boy, since his recovery from typhoid, "has never been himeelf," as stated by his parents. His former cheorfulness and general good health had gore. Since the attack he became irritable, peevish and illy nourished. A bout a year ago he had a marked recurrence of his otorrhea, with certain cerebral manifestations, as vomiting, nausea and vertigo, followed by a cessation of the discharge with coma, and, as a consequence, the inevitable-death--was looked for and so thought by his attendant physician. These are the statements of his father. After being given up to die, he took a turn for the better, following an escape of an immense amount of pus from his ear, and in twenty-four hours was upand about " the ear broke," and has continued well up to a week before I saw him, when Dr. Hartwig was asked to see him, the boy complaining of pain indefinitely located over right side of head, disebarge from ear being glight. Dr. Hartwig instituted the usual antiphologistic measures-washing ear, insuffltion of antiseptic powders, sedatives, etc., but in spite of these the pain continued and when I saw him on the eveuing of February 2 his irritability and pain were marked.

A careful examination revealed a small perforation at the anterior inferior quadrant, low down, little discharge, posterior segment of drum whitish and sodden looking, canal free except for slight swelling and redness anterior inferiorly. There was no redness nor tenderness over mastoid antrum or tip; temperature 99, pulse 72. The advisability of opening his mastoid for the relief of the continued pain, which would yield to no therapeutic measures, was considered, but we concluded to wait and watch until the next day, in the meantime employing seda tives, aconite, and ice-packs to the mastoid. On the following day his pain still continued, with no sleep at vight; no other symptoms were present; eye-grounds werenormal; speech was unaltered, intellect clear, no motor or sensory paralysis, no in co-ordination, no nausea or vomiting, no vertigo. On the afternoon of February 3 we prepared the boy for opening of the mastoid antrum. The boy was chloroformed and prepared in the usual way for such operations. On chiseling into the mas toid we found it dense, the antrum (small) boing reached at a depth of half an inch. A small amount of cholesteatomatous material was removed, the post superior wall of the meatus was partially knocked down and a curette passed into the tympanic cavity. Free communication was established between the external meatus and antrum, manifesced by syringing through the antrum into tympanic cavity and out at external meatus, and vice versa. The wound was dressed and the boy put to bed, followed by a good night's rest and cessation of pain on the following day. His temperature was normal, pulse slightly subnormal, varying from 60 to 65; appetite fair; no other phenomena except apathy with an occasional restless and irritable spell.

Dr. Hartwig watched the case daily from February 3 until February 7 ; the boy not showing signs of improvement he asked me to look at him, which I did on the evening of Febru. 